\title{
CÂNCER DE COLO DO ÚTERO, GENOTIPAGEM DO PAPILOMA- VÍRUS HUMANO (HPV) EM MULHERES QUILOMBOLAS DE UM MUNICÍPIO BRASILEIRO: ACEITABILIDADE DA VACINA*
}

CANCER OF THE CERVIX, GENOTYPING OF HUMAN PAPILLOMAVIRUS (HPV) IN QUILOMBOLA WOMEN IN A BRAZILIAN CITY: ACCEPTABILITY OF THE VAC-CINE.

EL CÁNCER DEL CUELLO UTERINO, LA GENOTIPIFICACIÓN DEL VIRUS DEL PAPILOMA HUMANO (VPH) EN MUJERES QUILOMBOLAS EN UNA CIUDAD BRASILEÑA: LA ACEPTABILIDAD DE LA VACUNA.

Isadora Clarissa Cordeiro Dias Graduanda em Medicina na Universidade Federal do Maranhão/UFMA

Maria do Desterro Soares Brandão Nascimento Pós-Doutorado pelo Programa de Pós-Graduação em Oncologia/INCA José Eduardo Batista
Doutorando em Medicina DINTER UFG/UEMA/UFMA/UESPI

Flávia Castello Branco Vidal Doutora em Biologia Humana e Experimental pela Universidade do Estado do Rio de Janeiro

Dulcelena Ferreira Silva Doutora em Fisiopatologia Clínica e Experimental pela Universidade do Estado do Rio de Janeiro

Marcos Antonio Custódio Neto da Silva Graduando em Medicina na Universidade Federal do Maranhão/UFMA

Fabiola Nassar Sousa Frazão Graduanda em Medicina na Universidade Federal do Maranhão/UFMA

Anna Cyntia Brandão Nascimento Graduada em Medicina pela Universidade de Ribeirão Preto/UNAERP

Geusa Felipa de Barros Bezerra Doutora em Biotecnologia pela Universidade Estadual do Ceará

Walbert Edson Muniz Filho Mestre em Bioquímica pela Universidade Federal do Ceará

Graça Maria de Castro Viana Doutora em Infectologia pela Universidade Federal de São Paulo

\footnotetext{
* Trabalho premiado durante o XXV Encontro do SEMIC, realizado na UFMA, entre os dias 18 a 22 de novembro de 2013. Artigo recebido em fevereiro de 2014

Aprovado abril de 2014
} 


\section{a r t i g o}

RESUMO: O câncer de colo uterino é o segundo câncer feminino mais comum no Brasil. O papilomavírus humano (HPV) é causa necessária para seu desenvolvimento. A vacina surge como uma arma contra a infecção por HPV e, consequentemente, contra o câncer. Mas existem mais de 100 genótipos diferentes de HPV, que são divididos em baixo risco e alto risco, de acordo com o potencial oncogênico. Analisam-se os aspectos epidemiológicos e biomoleculares da infecção por HPV na mucosa genital de mulheres quilombolas, verificando a associação os achados citológicos e biomoleculares e observando a frequência do papilomavírus nessa população e de seus tipos, para avaliar a aplicabilidade da vacina na população em estudo. A população deste estudo é de 101 mulheres pertencentes à comunidade quilombola de Ju-çatuba, no estado do Maranhão. Foram coletadas amostras de mucosa genital, submetidas à pesquisa para a presença do HPV pela técnica de PCR Nested. As amostras positivas foram sequenciadas para fins de genotipagem viral. Em uma população predominante de mulheres em idade fértil, com parceiro fixo e baixo nível de escolaridade, verificou-se que 10 amostras da cérvice uterina foram positivas para

HPV, sendo 7 positivas para os tipos de alto risco. Mediante a presença dos tipos virais de alta oncogenicidade, observa-se a necessidade de implementação de condutas gestoras para redução do risco de aparecimento de câncer do colo do útero.

Palavras-chave: Papilomavírus humano. Câncer. Colo uterino. Reação em cadeia da polimerase.

ABSTRACT: Cervical cancer is the second most common female cancer in Brazil. The human papilloma-virus (HPV) is a need cause for its development. The vaccine appears as a weapon against HPV infection and therefore against cancer. But there are more than 100 different HPV genotypes, which are divided into low risk and high risk according to the oncogenic potential. To analyze the epidemiological and biomolecu-lar aspects of HPV infection in the genital mucosa of women Maroons, verifying the association cytological and molecular biological findings and noting the frequency of this population papillomavirus and its types, to evaluate the applicability of the vaccine in the study population. The study population was 101 women belonging to the maroon community of Juçatuba in the state of Maranhão. Genital mucosa samples were collected and submitted to search for the presence of HPV by PCR Nested. The positive samples were sequenced for the purpose of viral genotyping. In a predominant population of women of childbearing age, with a steady partner, and low level of education, it was found that 10 samples of uterine cervix were positive for HPV, with 7 positive for high-risk types. Through the presence of viral types of high tumorige-nicity, there is a need to implement management practices for reducing the risk of developing cancer of the cervix.

KEYWORDS: Human Papillomavirus. Cancer. Cervix. Polymerase Chain Reaction.

RESUMEN: El cáncer cervical es el segundo cáncer femenino más común en Brasil. El virus del papiloma humano (VPH) es la causa necesaria para su desarrollo. La vacuna se presenta como un arma contra la infección por VPH y, por tanto, contra el cáncer. Pero hay más de 100 genotipos diferentes de VPH, que se dividen en bajo riesgo y de alto riesgo de acuerdo con el potencial oncogénico. Analizar los aspectos epidemiológicos y biomoleculares de la infección por el VPH en la mucosa genital de la mujer cimarrones, la verificación de la citología asociación y hallazgos de biología molecular y tomando nota de la frecuen-cia de este virus del papiloma de la población y sus tipos, para evaluar la aplicabilidad de la vacuna en la población de estudio. La populación de estudio fue de 101 mujeres pertenecientes a la comunidad marrón de Juçatuba en el Estado de Maranhão. Se recogieron muestras de mucosa genital presentados para buscar la presencia de VPH por PCR anidada. Las muestras positivas se secuenciaron con el propósito de determinación del genotipo viral . RESULTADOS: En una población predominante de las mujeres en edad fértil, con una pareja estable, y el bajo nivel de la educación, se encontró que 10 muestras fueron positivas para el VPH cervical, 7 siendo positivo para los tipos de alto riesgo. A través de la presencia de tipos virales de alta tumorigenicidad, hay una necesidad de aplicar prácticas de gestión para reducir el riesgo de desarrollar cáncer de la cérvix.

PALABRAS CLAVE: Virus del papiloma humano. Cáncer. Cérvix. Reacción en Cadena de la Polimerasa. 
CÂNCER DE COLO DO ÚTERO | Isadora Clarissa Cordeiro Dias et al.

\section{1 | Introdução}

O papilomavírus humano (HPV) é o agente viral sexualmente transmissível mais comum em mulheres em âmbito mundial (WORLD HEALTH ORGANIZATION, 2012). É um vírus de DNA circular de dupla fita, cujo genoma pode ser dividido em duas regiões codificantes e uma região não codificante (HAUSEN, 2002). Existem atualmente mais de 100 genótipos diferentes de HPV e são divididos em baixo risco e alto risco. Os tipos de baixo risco estão associados ao surgimento de lesões benignas como verrugas (HPVs tipo 6, 11, 40, 42, 43, 44, 54, 61, 70, 72, 81 e CP6108), e os de alto risco estão associados ao processo de carcinogênese (HPVs tipo 16, 18, 31, 33, 35, 39, 45, $51,52,54,56,58,59,66,68,73,82,26,53$ e 66), sendo os tipos HPV 16 e 18 relaciona-dos a mais de $70 \%$ dos casos de câncer cervical (CUTTS et al., 2007; NORONHA et al., 2007).

O câncer do colo do útero é uma doença que atinge mulheres em todo o mundo, com uma estimativa de 500 mil novos casos e aproximadamente 274 mil óbitos por ano (WORLD HEALTH ORGANIZATION, 2012). É o segundo câncer que mais acomete as mulheres e o terceiro mais letal (CASTELLSAGUÉ et al., 2007). As estimativas no Brasil apontam para a ocorrência de 17.540 novos casos de câncer de colo do útero por ano. No Maranhão, é o primeiro em mortalidade feminina. (INSTITUTO NACIONAL DO CÂNCER, 2011).

Historicamente, a associação entre os vírus do papiloma humano (HPV) e câncer do colo do útero foi sugerida por Harald Zur Hausen, em 1974. Entretanto o HPV, isoladamente, não é capaz de causar o desenvolvimento do câncer, representando um dos múltiplos fatores envol-vidos na oncogênese cervical, tal como a amplitude da lesão na cérvice uterino (BEHBAKHT et al., 2002; CÂMARA et al., 2003). Contudo, o desenvolvimento e aprimoramento de técnicas de análises laboratoriais permitiram a comprovação epidemiológica do HPV como causa necessária para o câncer de colo do útero (MACHADO, 2007). Tais técnicas laboratoriais permitem identi-ficar a presença do HPV no epitélio cervical, detectando e tipificando o HPV, quando presente.

O avanço tecnológico e a evolução das técnicas moleculares tornaram real a imunização con-tra o HPV. Existem duas vacinas profiláticas disponíveis contra o HPV: uma bivalente, contra os tipos oncogênicos mais prevalentes, HPV 16 e 18; e outra tetravalente que, além destes, inclui também os tipos virais de baixo risco mais comuns, os HPVs 6 e 11 (VILLA et al., 2007). Am-bas produzidas por meio de engenharia genética, utilizando a tecnologia do DNA recombinante

(LOWY; SCHILLER, 2006). Por serem destituídas do genoma viral, não possuem capacidade infectante, nem replicativa nem oncogênica (CASTELLSAGUÉ et al., 2007).

Os pais têm um papel ativo no processo de tomada de decisão quanto à decisão de vacinação contra o HPV, influenciados por muitos fatores utilizados pelos clínicos ao recomendar a vacina e intervenções de captação futuras vacinas. Os níveis de conhecimento dos pais e de mulheres jovens sobre a vacina, contra o câncer cervical e HPV são altamente importantes para a expan-são da vacinação (ALEXANDER et al., 2012).

Este trabalho permite a observação da frequência de HPV encontrada em mulheres quilombolas, a partir de que pode ser avaliada a aplicabilidade da vacina nesta população. Objetivou-se analisar os aspectos epidemiológicos e biomoleculares da infecção por HPV, verificando a associação dos achados citológicos e biomoleculares e o potencial oncogênico da infecção pelo HPV.

\section{2 | Metodologia}

Realizou-se um estudo prospectivo, descritivo e analítico para pesquisa do câncer de colo do útero e da infecção por HPV. A população selecionada para este estudo é constituída por 101 mulheres, pertencentes à comunidade quilombola de Juçatuba, município de São José de Ribamar, Estado do Maranhão. Foi considerado como critério de inclusão ser afrodescendente e pertencer a uma das comunidades quilombolas em estudo. As mulheres foram atendidas pela 
equipe do projeto de pesquisa da Universidade Federal do Maranhão no Posto de Saúde da Es-tratégia de Saúde da Família existente na comunidade quilombola.

Por meio de escova endocervical, foi coletado material de cérvice uterina, realizando-se esfregaço celular em lâmina de vidro, fixado em álcool e encaminhado para o Núcleo de Imunologia Básica e Aplicada (NIBA) da Universidade Federal do Maranhão (UFMA), onde foram submetidas à coloração pela técnica de Papanicolaou e exame, determinando a frequência de anormalidades citológicas.

Todas as amostras foram analisadas para a presença do HPV pela técnica de PCR Nes-ted, com o objetivo de determinar a prevalência do vírus em mulheres quilombolas. As amostras positivas foram sequenciadas para fins de genotipagem viral. Para tais procedimentos, foi realizada coleta de material celular com escova estéril do kit hc2 DNA Collection Device (QIAGEN,

Valencia, CA). O material foi colocado em tubo com $1 \mathrm{ml}$ de meio de transporte de amostra (contendo azida sódica) do mesmo kit e congelado a $-20^{\circ} \mathrm{C}$. Na reação de PCR Nested foram utilizados na primeira rodada os primers PGMY 09 e PGMY11, no segundo round os primers GP +5 e GP+6. O material biológico foi armazenado no Banco de Tumores e DNA do Estado do Maranhão (BTMA-UFMA) e as reações foram realizadas no Laboratório Multiusuário.

Os produtos de PCR foram purificados com o kit PureLink ${ }^{\mathrm{TM}}$ (Invitrogen, Carlsbad, Califórnia). A cada microtubo foi adicionado tampão de captura a $100 \mu \mathrm{L}$ de produto de PCR. Esta solução foi transferida a uma coluna Microspin com tubo coletor e depois de uma série de lavagens com tampões, foi adicionado ao centro da coluna $25 \mu \mathrm{L}$ de tampão de eluição. $\mathrm{O}$ material foi centrifu-gado e $2 \mu \mathrm{L}$ do DNA purificado foi submetido a uma corrida eletroforética em gel de agarose $2 \%$ para avaliação da amostra purificada. Por fim, este material foi reservado a - 20 ○C para posterior sequenciamento automático.

As reações de sequenciamento foram realizadas no Departamento de Genética do Instituto Nacional de Câncer José Alencar Gomes da Silva (INCA). O sequenciamento foi realizado com o kit ET Dye Terminator Cycle Sequencing kit (GE Healthcare, UK), de acordo com o protocolo do fabricante. Foram utilizados, em cada reação, $2 \mu \mathrm{L}$ do produto de PCR purificado, 40 ng dos oligonucleotídeos específicos para cada exon (senso ou antisenso) e $2 \mu \mathrm{L}$ do kit. $\mathrm{O}$ seqüenciador automático utilizado foi o MegaBACE 1000 (GE Healthcare, UK).

\section{3 | Resultados}

\section{1 | Dados sócio-demográficos}

No presente estudo foram coletadas amostras de cérvice uterina de 101 mulheres pertencentes à comunidade quilombola de Juçatuba, município de São José de Ribamar, Estado do Maranhão.

$\mathrm{Na}$ análise dos dados sócio-demográficos, a faixa etária predominante foi de 30 - 40 anos (26,7\%;27/101), com média de idade de 41,9 anos. Quanto à raça, 77,2\% (78/101) das mulhe-res eram pardas. Quanto ao estado civil, 59,4\% eram casadas (60/101). Quanto à escolaridade, $42,5 \%$ possuíam o ensino fundamental incompleto (43/101). As profissões mais encontradas foram: lavradora (31,7\%;32/101) e do lar (27,7\%;28/101); Quanto ao grau de nutrição, 43,5\% (44/101) das mulheres eram eutróficas; 56,4 \% das mulheres (57/101) afirmaram ser etilistas e $100 \%$ afirmou ser não fumante (tabela 1 ). 
CÂNCER DE COLO DO ÚTERO | Isadora Clarissa Cordeiro Dias et al.

Tabela 1 - Dados sócio-demográficos de mulheres quilombolas de Juçatuba submetidas ao rastreamento por HPV em amostras da cérvice no período de 2010 a 2012

\begin{tabular}{|c|c|c|}
\hline Variáveis & F & $\%$ \\
\hline \multicolumn{3}{|l|}{ Idade } \\
\hline$<20$ & 04 & 4,0 \\
\hline $20 \mid-30$ anos & 23 & 22,7 \\
\hline $30 \mid-40$ anos & 27 & 26,7 \\
\hline $40 \mid-50$ anos & 17 & 16,8 \\
\hline $50 \mid-60$ & 17 & 16,8 \\
\hline $601-70$ & 10 & 10,0 \\
\hline$>70$ & 03 & 3,0 \\
\hline \multicolumn{3}{|l|}{ Raça } \\
\hline Parda & 78 & 77,2 \\
\hline Negra & 22 & 21,8 \\
\hline Branca & 01 & 1,0 \\
\hline \multicolumn{3}{|l|}{ Estado civil } \\
\hline Casada & 60 & 59,4 \\
\hline União Estável & 18 & 17,8 \\
\hline Solteira & 15 & 14,8 \\
\hline Viúva & 07 & 7,0 \\
\hline Divorciada & 01 & 1,0 \\
\hline \multicolumn{3}{|l|}{ Escolaridade } \\
\hline Analfabeta & 01 & 1,0 \\
\hline Fundamental completo & 06 & 6,0 \\
\hline Fundamental incompleto & 43 & 42,5 \\
\hline Médio completo & 38 & 37,6 \\
\hline Médio incompleto & 06 & 6,0 \\
\hline Superior completo & 03 & 2,9 \\
\hline Superior incompleto & 04 & 4,0 \\
\hline \multicolumn{3}{|l|}{ Profissão } \\
\hline Aposentada & 04 & 4,0 \\
\hline Autônoma & 02 & 2,0 \\
\hline Agente de Saúde & 01 & 1,0 \\
\hline Auxiliar Operacional de Serviços Diversos & 04 & 4,0 \\
\hline Auxiliar de Serviços Gerais & 03 & 2,9 \\
\hline Auxiliar de Consultório Dentáno & 01 & 1,0 \\
\hline Do lar & 28 & 27,7 \\
\hline Empregada Doméstica & 05 & 4,9 \\
\hline Embaladora & 01 & 1,0 \\
\hline Estudante & 02 & 2,0 \\
\hline Feirante & 01 & 1,0 \\
\hline Funcionánia Pública & 02 & 2,0 \\
\hline Lavradora & 32 & 31,7 \\
\hline Pescadora & 01 & 1,0 \\
\hline Professora & 11 & 10,9 \\
\hline Técnica de Enfermagem & 02 & 2,0 \\
\hline Vendedora & 01 & 1,0 \\
\hline \multicolumn{3}{|l|}{ Grau de Nutrição } \\
\hline Desnutrição & 03 & 3,0 \\
\hline Eutrofia & 44 & 43,5 \\
\hline Sobrepeso & 31 & 30,8 \\
\hline Obesidade & 23 & 22,7 \\
\hline \multicolumn{3}{|l|}{ Etilismo } \\
\hline Sim & 57 & 56,4 \\
\hline Não & 44 & 43,6 \\
\hline \multicolumn{3}{|l|}{ Tabagismo } \\
\hline Sim & Q & 0,0 \\
\hline Não & 101 & 100,0 \\
\hline
\end{tabular}

Fonte: Elaborado pelos autores 
CÂNCER DE COLO DO ÚTERO | Isadora Clarissa Cordeiro Dias et al.

\section{2 | Dados reprodutivos}

A análise dos dados reprodutivos evidenciou que $92 \%$ das mulheres estudadas já haviam rea-lizado exame preventivo, sendo que 39,6\% das mulheres realizaram o exame em 2010. Quanto ao uso de métodos contraceptivos 56,5\% não utilizavam nenhum método, sendo que 96\% não utilizavam pílula anticoncepcional (tabela 2).

No momento do estudo, $3 \%$ das mulheres estavam grávidas, sendo que $66,3 \%$ das mulheres haviam tido entre $0-4$ gestações pregressas. $75 \%$ das mulheres haviam realizado parto vaginal e 31,7\% estavam no período da menopausa (tabela 2).

Quanto ao parceiro sexual atual, 78,2\% apresentavam parceiro fixo e durante a vida sexual, $55,4 \%$ das mulheres tiveram apenas um parceiro (tabela 2 ).

Quando questionadas sobre a aceitabilidade da vacina contra o HPV para suas filhas na faixa etária preconizada pelo Ministério da Saúde, 100\% das pacientes responderam afirmativamente.

Tabela 2 - Dados reprodutivos de mulheres quilombolas de Juçatuba submetidas ao rastreamento por HPV em amostras da cérvice no período de 2010 a 2012

\begin{tabular}{|c|c|c|}
\hline Variáveis & $\mathbf{F}$ & $\%$ \\
\hline \multicolumn{3}{|c|}{ Exame Preventivo } \\
\hline Sim & 93 & 92,0 \\
\hline Não & 08 & 8,0 \\
\hline \multicolumn{3}{|c|}{ Ano de realização do último preventivo } \\
\hline 2011 & 32 & 31,7 \\
\hline 2010 & 40 & 39,6 \\
\hline 2009 & 14 & 13,9 \\
\hline$<2009$ & 06 & 5,9 \\
\hline Nãosabe & 01 & 1.0 \\
\hline Não realizou & 08 & 7,9 \\
\hline \multicolumn{3}{|c|}{ Uso de método contraceptivo } \\
\hline Sim & 44 & 43,5 \\
\hline Não & 57 & 56,5 \\
\hline \multicolumn{3}{|c|}{ Uso de pilula anticoncepcional } \\
\hline Sim & 04 & 4,0 \\
\hline Não & 97 & 96,0 \\
\hline \multicolumn{3}{|l|}{ Gravidez atual } \\
\hline Sim & 03 & 3,0 \\
\hline Não & 98 & 97,0 \\
\hline \multicolumn{3}{|c|}{ Número de gestações } \\
\hline $0-4$ & 67 & 66,3 \\
\hline $5-9$ & 27 & 26,7 \\
\hline$\geq 10$ & 07 & 7,0 \\
\hline \multicolumn{3}{|l|}{ Partos } \\
\hline Vaginal & 76 & 75,2 \\
\hline Cesáreo & 36 & 35,6 \\
\hline Abortamento & 31 & 30,7 \\
\hline \multicolumn{3}{|l|}{ Menopausa } \\
\hline Sim & 32 & 31,7 \\
\hline Não & 69 & 68,3 \\
\hline \multicolumn{3}{|l|}{ Curetagem } \\
\hline Sim & 09 & 90,0 \\
\hline Não & 91 & 10,0 \\
\hline \multicolumn{3}{|c|}{ Parceiro sexual fixo atualmente } \\
\hline Sim & 79 & 78,2 \\
\hline Não & 22 & 21,8 \\
\hline \multicolumn{3}{|c|}{ Número de parceiros na vida } \\
\hline Um & 56 & 55,4 \\
\hline Dois & 23 & 22,8 \\
\hline Três ou mais & 22 & 21,9 \\
\hline \multicolumn{3}{|c|}{ Aceitabilidade da vacina para suas filhas } \\
\hline Sim & 101 & 100,0 \\
\hline Não & 0 & 0,0 \\
\hline
\end{tabular}

Fonte: Elaborado pelos autores 
CÂNCER DE COLO DO ÚTERO | Isadora Clarissa Cordeiro Dias et al.

\section{3 | Dados citopatológicos}

$\mathrm{Na}$ avaliação citopatológica, $80,2 \%$ das mulheres apresentavam alterações no colo; o epitélio escamoso + glandular foi encontrado em $47,5 \%$ das amostras (tabela 3 ).

O resultado da microbiologia no exame citológico mostra a predominância de Lactobacillus $s p$ $(36,6 \%)$ e Gardnerella vaginalis (22,8\%). Quanto às alterações benignas ou reparativas, inflama-ção foi encontrada em $80,2 \%$, atrofia em $5,9 \%$ e lesão intra-epitelial de alto grau em $3,9 \%$ das pacientes (Tabela 3 ).

Tabela 3 - Dados citopatológicos de mulheres quilombolas de Juçatuba submetidas ao rastreamento por HPV em amostras da cérvice no período de 2010 a 2012

\begin{tabular}{|c|c|c|}
\hline Variáveis & $\mathbf{F}$ & $\%$ \\
\hline \multicolumn{3}{|l|}{ Inspeção do Colo } \\
\hline Normal & 18 & 17,8 \\
\hline Alterado & 81 & 80,2 \\
\hline Não visualiza do & 02 & 2,0 \\
\hline \multicolumn{3}{|l|}{ Sinais de doenças sexualmente transmissiveis } \\
\hline Sim & 69 & 68,3 \\
\hline Não & 32 & 31,7 \\
\hline \multicolumn{3}{|l|}{ Epitélios representados na amostra } \\
\hline Escamoso & 25 & 24,7 \\
\hline Glandular & 01 & 1,0 \\
\hline Escamoso + Glandular & 48 & 47,5 \\
\hline Escamoso + Metaplástico & 04 & 4,0 \\
\hline Escamoso + Glandular + Metaplástico & 23 & 22,8 \\
\hline \multicolumn{3}{|l|}{ Alterações celulares benignas ou reparativas } \\
\hline Atrofia & 06 & 5,9 \\
\hline Inflamação & 81 & 80,2 \\
\hline Inflamação + Citólise & 02 & 2,0 \\
\hline Inflamação + Reparo & 02 & 2,0 \\
\hline LSIL & 01 & 1,0 \\
\hline LSIL-H & 02 & 2,0 \\
\hline HSIL & 04 & 3,9 \\
\hline ASC-H & 01 & 1,0 \\
\hline ASC-US & 02 & 2,0 \\
\hline \multicolumn{3}{|l|}{ Microbiologia } \\
\hline $\operatorname{Cocos}$ & 10 & 10,0 \\
\hline Bacilos & 06 & 5,9 \\
\hline Cocos + Bacilos & 06 & 5,9 \\
\hline Cocos + Bacilos + Candida SP & 01 & 1,0 \\
\hline Bacilos + Candida $S P$ & 01 & 1,0 \\
\hline Lactobacillus $S P$ & 37 & 36,6 \\
\hline Lactobacillus sp + Cocos & 02 & 1,9 \\
\hline Lactobacillussp + Candida SP & 06 & 6,0 \\
\hline Lactobacillus sp + Leptotrix vaginalis & 01 & 1,0 \\
\hline Gardnerella vaginalis & 23 & 22,8 \\
\hline Gardnerella vaginalis + Trichomonas vaginalis & 01 & 1,0 \\
\hline Flora escassa & 07 & 6,9 \\
\hline
\end{tabular}

Legenda: LSIL (lesão intra-epitelial de baixo grau); HSIL (lesão intra-epitelial de alto grau). Fonte: Elaborado pelos autores 
CÂNCER DE COLO DO ÚTERO | Isadora Clarissa Cordeiro Dias et al.

A biologia molecular resultou em amostras de 10 pacientes positivas para a infecção por HPV na reação de PCR Nested, sendo 7 de alto risco e 4 mulheres foram diagnosticadas com HPV de baixo risco. (tabela 4 e gráfico 1).

Tabela 4 - Dados moleculares de mulheres quilombolas de Juçatuba submetidas ao rastreamento por HPV em amostras da cérvice no período de 2010 a 2012

\begin{tabular}{lcc}
\hline Variáveis & F & $\%$ \\
\hline Presença do HPV & & \\
Sim & 11 & 10,9 \\
Não & 82 & 81,2 \\
GADPH - & 08 & 7,9 \\
Classificação do HPV & & \\
Alto risco & 07 & 63,6 \\
Baixo risco & 04 & 36,4 \\
\end{tabular}

Legenda: GADPH- (Ausência de DNA na amostra isolada)

Fonte: Elaborado pelos autores

Os tipos de HPV encontrados nas amostras de cérvice de mulheres quilombolas de Juçatuba submetidas ao rastreamento de HPV (genotipagem), em amostras da cérvice no período de 2010 a 2012 compreenderam 7 de alto risco $(56,68,59,66,39,70,52)$ e 3 mulheres diagnosticadas com HPV de baixo risco $(84,62,72)$.

\section{4 | Discussão}

As infecções por HPV anogenital são as doenças sexualmente transmissíveis mais comuns. Os tipos de HPV dessa região têm sido amplamente classificados como de baixo risco e incluem os tipos 6 e 11 que são associados com verrugas anogenitais e displasia leve. Os de alto risco, os tipos 16, 18, 31 e 45 são associados com displasia de alto grau e cânceres genitais, como o carcinoma cervical e anal (CATES JR., 1999; WEINSTOCK; BERMAN; CATEST JR., 2004).

O avanço tecnológico e a evolução das técnicas moleculares tornaram a detecção do HPV cada vez mais precisa, permitindo o diagnóstico precoce e o acompanhamento de pacientes po-sitivas a fim de evitar a evolução do câncer, bem como conhecer a epidemiologia do HPV para que se possa promover ações de controle mais eficazes contra este patógeno.

Os HPV de alto risco têm sido encontrados em proporções muito elevadas em mulheres com câncer invasivo e lesões pré-invasivas de alto grau através de técnicas de biologia molecular (PCR e cultura híbrida II) (IGANSI, 2005).

Quanto aos dados sócio-demográficos, a média de idade do estudo foi diferente do encontrado por Pinto, Fuzzi e Quaresma (2011), que encontraram média de 34,1 anos em população rural da Amazônia.

A presença de coinfecções genitais, transmitidas sexualmente ou não, podem ser de importância para o aparecimento de condilomas genitais, devido ao aumento da secreção vaginal e aumento da umidade, que propicia um local adequado à sobrevivência e multiplicação viral. Microrganismos transmitidos por via sexual podem interagir de maneira mais efetiva com o $\mathrm{Pa}$ pilomavírus Humano, uma vez que apresentam a mesma via de transmissão (RIBEIRO et al., 2007). Por isso é tão comum a presença de coinfecções em presença de HPV, neste trabalho tendo destaque a Gardnerella vaginalis.

Nos achados da citologia, estudo realizado na Amazônia com 444 mulheres encontrou 97,2\% 
CÂNCER DE COLO DO ÚTERO | Isadora Clarissa Cordeiro Dias et al.

de normalidade ou inflamação (KEITA et al., 2009), semelhante ao encontrado nesse estudo. Quanto às alterações benignas, o resultado encontrado concorda com os achados de Keita et al. (2009), que encontraram 1,9\% de ASC-US e 1,8\% de HSIL.

$\mathrm{Na}$ análise da prevalência do HPV na população estudada, Pinto, Fuzzi e Quaresma (2011) encontraram 11,6\% de infecção, semelhante ao encontrado neste estudo. Quanto à prevalência de HPV de alto risco, o estudo foi semelhante aos achados de Keita et al. (2009), que encon-traram 73,3\% tipos virais de alto risco. No Brasil, Trottier et al. 16 apontaram uma frequência de 10,6\% de HPV em mulheres de 18 a 60 anos, enquanto Franco et al. (1999) apontaram a pre-valência inicial de HPV de $13,8 \%$ para mulheres na mesma faixa de idade.

O papel dos pais na decisão com relação à vacinação de suas filhas é fundamental (ALEXANDER et al., 2012). Aqui se destaca o posicionamento positivo de todas as mães questionadas. Este é, portanto, um fator de estímulo à vacinação, visto que inicialmente já tem excelente aceitação popular. Fica para os médicos e demais profissionais de saúde o dever sobre os esclarecimentos, ao recomendar a vacina (ALEXANDER et al., 2012).

A vacina tetravalente tem eficácia de $100 \%$ na inibição da infecção por HPV dos tipos específicos que atinge (VILLA et al., 2007). A aceitabilidade da vacina para o HPV promove enormes benefícios para a saúde pública (GARNETT et al., 2006; BOSCH; CASTELLSAGUE; SANJOSÉ, 2008; GOLDHAVER-FIEBERT et al., 2008) e deve ser administrada antes do início da atividade sexual (STANLEY; LOWY; FRAZER, 2006; MARKOWITZ et al., 2007; SASLOW et al., 2007).

Trabalho realizado por Fregnani et al. (2013) em um município de São Paulo, mostrou aceitabilidade de $96,1 \%$. Este trabalho mostra que a aceitabilidade da vacina foi de $100 \%$, o que reforça a estratégia do Ministério da Saúde de vacinar meninas de 9-13 anos como forma de prevenção.

\section{5 | Considerações finais}

Os dados sócio-demográficos mostraram que a faixa etária predominante das mulheres quilombolas em estudo foi de 30 - 40 anos (26,7\%;27/101), com média de idade de 41,9 anos. Quanto à escolaridade, 42,5\% possuíam o ensino fundamental incompleto (43/101). As profissões mais encontradas foram: lavradora $(31,7 \% ; 32 / 101)$ e do lar $(27,7 \% ; 28 / 101)$; Quanto ao grau de nutrição, 43,5\% (44/101) das mulheres eram eutróficas; 56,4 \% das mulheres (57/101) afirmaram ser etilistas e 100\% afirmou ser não fumante.

O exame colpocitológico demonstrou a predominância de Lactobacillus sp (36,6\%) e Gardnerella vaginalis $(22,8 \%)$. Quanto às alterações benignas ou reparativas, inflamação foi encontrada em $80,2 \%$, atrofia em 5,9\% e lesão intra-epitelial de alto grau em 3,9\% das pacientes.

$\mathrm{Na}$ comunidade quilombola em estudo, detectraram-se amostras da cérvice de 10 pacientes positivas para a infecção por HPV, sendo 7 de alto risco $(56,68,59,66,39,70,52)$ e 3 mulheres diagnosticadas com HPV de baixo risco $(84,62,72)$.

Esta pesquisa mostra que a aceitabilidade da vacina pelas mulheres a fim de imunizar suas filhas foi de $100 \%$, o que reforça a estratégia do Ministério da Saúde como forma de prevenção.

É importante que mais trabalhos de descrição dos tipos virais prevalentes nas diversas popu-lações sejam realizados, para possibilitar novos estudos e desenvolvimento de possíveis outras vacinas para os demais tipos de HPV.

Condutas de gestão devem ser implementadas para redução do risco de aparecimento de câncer do colo do útero, o que evidencia a relevância desta investigação acerca da presença do HPV nessa população. É necessária a comparação das estratégias de rastreio de câncer cervical incorporando diferentes combinações de técnicas com a citologia oncótica cervico-vaginal, tais como o teste molecular de HPV e sua genotipagem. 
CÂNCER DE COLO DO ÚTERO | Isadora Clarissa Cordeiro Dias et al.

\section{Agradecimentos}

À Fundação de Amparo à Pesquisa e ao Desenvolvimento Científico e Tecnológico do Estado do Maranhão. EDITAL N. 012/2009 - PPSUS. Processo - PPSUS-01363/09 pelo fomento con-cedido. 


\section{Referências}

ALEXANDER A B et al. Parent-son decision-making about human papillomavirus vaccination: a qualitative analysis. BMC Pediatrics, v. 12, p. 192, 2012.

BEHBAKHT, K. et al. Role of the vaginal microbiological ecosystem and cytokine profile in the promotion of cervical dysplasia: a case-control study. Infections diseases in obstetrics and gynecology, New York, v. 10, n. 4, p. 181-186, 2002.

BOSCH, F X.; CASTELLSAGUÉ, X.; SANJOSÉ, S. de. HPV and cervical cancer: screening or vaccination? $\mathrm{Br} J$ Cancer, v. 98, p. 15-21, 2008.

CAMARA, G. N. et al. Prevalence of human papillomavirus types in women with pre-neoplastic and neoplastic cervical lesions in the Federal District of Brazil. Mem Inst Oswaldo Cruz, v. 98, n. 7, p. 879-883, 2003.

CASTELLSAGUÉ, $X$. et al. HPV and cervical cancer in the world: 2007 report. Vaccine, v. 25, p. 1-230, nov. 2007.

CATES Jr, W. Panel. Estimates of the incendence and a prevalence of sexually transmitted disease in the United States: american social health association. Sex Transm Dis, v. 26, p. 2-7, Apr. 1999.

CUTTS, F. T. et al. Human papillomavirus and HPV vacci nes: a review. Bull of the Health Organization, v. 85, n. 9, p. 719-726, Sept. 2007.

FRANCO E. L. et al. Epidemiology of acquisition and clearance of cervical human papillomavirus infection in women from a high-risk area for cervical cancer. J Infect Dis v. 180, n. 5, p. 1415-1423, Nov. 1999.

FREGNANI J. H. et al. A school-based human papillomavirus vaccination program in barretos, brazil: final results of a demonstrative study. PLoS One. v. 8, n. 4, Apr. 2013.

GARNETT, G. P. et al. Chapter 21: modelling the impact of HPV vaccines on cervical cancer and screening program-mes. Vaccine, v. 24, p. 178-186, Aug. 2006.

GOLDHABER-FIEBERT, J. D. et al. Cost-effectiveness of cervical cancer screening with human papillomavirus DNA testing and HPV-16, 18 vaccination. J Natl Cancer Inst, v. 100 , n. 5, p. 308-320, Mar. 2008.

IGANSI, C. N. Prevalência de papilomavírus humano (HPV) e chlamydia trachomatis (CT) e sua associação com lesões cervicais em uma amostra de mulheres assinto-máticas em Porto Alegre, Brasil. Estudo sobre variações no método de citologia em meio líquido para o exame de Papanicolau. 2005. Dissertação (Mestrado em Epidemiologia)-Universidade Federal do Rio Grande do Sul, Porto Alegre, 2005.

INSTITUTO NACIONAL DO CÂNCER. Estimativas 2012: incidência de câncer no Brasil. Rio de Janeiro: INCA, 2011.

KEITA, N. et al. HPV infection in women with and without cervical cancer in Conakry, Guinea. British Journal of Can- cer, v. 101, n. 1, p. 202-208, July 2009.

LOWY, D.R.; SCHILLER, J.T. Prophylactic human papillomavirus vaccines. J Clin Invest., v. 116, n. 5, p. 11671173, 2006.

MACHADO, J. P. Estudo sobre variações no método de citologia em meio líquido para o exame de Papanicolaou. 2007. Dissertação (Mestrado em Ciências Farmacêuticas)-Universidade Federal do Paraná, Curitiba, 2007.

MARKOWITZ, L. E. et al. Quadrivalent human papillomavi - rus vaccine: recommendations of the Advisory Committee on Immunization Practices (ACIP). MMWR Recomm Rep, v. 56, n. 2, p. 1-24, Mar. 2007.

NORONHA, V.L. et al. Papilomavírus humano (HPV) em mulheres submetidas a rastreamento para câncer de cérvice uterina. Belém-Pará-Brasil. J bras Doenças Sex Transm, v. 23, n. 1, p. 5-11, 2011.

WORLD HEALTH ORGANIZATION. International Agency for Research on Cancer. Globocan 2012: estimated cander incidence, mortality and prevalence worldwine in 2012. Disponível em: <http://globocan.iarc.fr/>. Acesso em: 19 dez. 2013.

PINTO, D. S.; FUZZI, H. T.; QUARESMA, J. A. S. Prevalên-cia de infecção genital pelo HPV em populações urbana e rural da Amazônia Oriental Brasileira. Cad. Saúde Pública,

Rio de Janeiro, v. 27, n. 4, p. 769-778, 2011.

RIBEIRO, A. A. et al. Agentes microbiológicos em exames citopatólogicos: estudo de prevalência. RBAC, v. 39, n. 3, p. 179-181, 2007.

SASLOW, D. et al. American cancer society guideline for human papillomavirus (HPV) vaccine use to prevent cervi cal cancer and its precursors. Ca: Cancer J Clin, v. 57, n. 1, p. 7-28, Jan./Feb. 2007.

STANLEY, M.; LOWY, D. R.; FRAZER, I. Prophylactic HPV vaccines: underlying mechanism. Vaccine, v. 24, p. 106-113, Aug. 2006.

TROTTIER, H. et al. Type-specific duration of human papillomavirus infection: implications for human papillomavirus screening and vaccination. J Infect Dis, v. 197, n. 10, p. 1436-1447, May 2008.

VILLA, L.L. et al. Prophylactic efficacy of a quadrivalent human papillomavirus (HPV) vaccine in women with virological evidence of HPV infection. Journal of Infectious Disea-ses, v. 196, n. 10, p. 1438-1446, Nov. 2007.

WEINSTOCK, H.; BERMAN, S.; CATES JR, W.. Sexualy transmitted disease among American youth: incidence and prevalence estimates, 2008. Pespect Sex Reprod Health, v. 36, n. 1, p. 6-10, Jan./Fev.2004.

ZUR HAUSEN, H. Papillomaviruses and cancer: from basic studies to clinical application. Nat Rev Cancer, v. 2, n. 5, p. 342-350, May 2002. 